\title{
Preparative Isolation of Anthraquinones from the Fungus Dermocybe sanguinea Using Enzymatic Hydrolysis by the Endogenous $\beta$-Glucosidase
}

\author{
Paavo H. Hynninen ${ }^{\mathrm{a}, *}$, Riikka Räisänen ${ }^{\mathrm{a}}$, Pia Elovaara ${ }^{\mathrm{b}}$ and Eila Nokelainen ${ }^{\mathrm{b}}$ \\ a Department of Chemistry, PO Box 55, University of Helsinki, FIN-00014 Helsinki, Finland. \\ Fax:+358-9-19140466. E-mail: Paavo.Hynninen@Helsinki.FI \\ b Department of Biochemistry, PO Box 1627, University of Kuopio, FIN-70211 Kuopio, \\ Finland \\ * Author for correspondence and reprint requests \\ Z. Naturforsch. 55c, 600-610 (2000); received March 22/April 25, 2000 \\ $\beta$-Glucosidase, Enzymatic Hydrolysis, Natural Anthraquinone
}

\begin{abstract}
A new and simple enzymatic method was developed for preparative isolation of anthraquinone pigments from Dermocybe sanguinea. The endogenous $\beta$-glucosidase of the fungus was used to catalyze the hydrolysis of the $O$-glycosyl linkage in emodin- and dermocybin- $1-\beta-\mathrm{D}-$ glucopyranosides. The developed enzymatic method was found to be effective for the pigment isolation, as the hydrolysis occurred virtually completely, thus leading to a high pigment yield. Two fractions were obtained by the method: Fraction 1 (94\% of the total pigment amount), containing almost exclusively the main pigments emodin and dermocybin, and Fraction $2(6 \%)$, containing the anthraquinone carboxylic acids. A $10.5 \mathrm{~kg}$ amount of fresh fungi yielded $56 \mathrm{~g}$ of Fraction 1 and $3.3 \mathrm{~g}$ of Fraction 2 anthraquinones. The anthraquinones in each fraction were separated by thin-layer chromatography using toluene-ethyl acetateethanol-formic acid $(10: 8: 1: 2, \mathrm{v} / \mathrm{v} / \mathrm{v} / \mathrm{v})$ as eluent. The components on the chromatograms were detected and characterized by measurements on a densitometer-spectrophotometer. Combined gas chromatography-mass spectrometry was applied to determine the anthraquinone derivatives of Fraction 1 after methylation and acetylation.
\end{abstract}

\section{Introduction}

Anthraquinone derivatives form the largest group of natural quinones. Approximately half of the various molecular species of natural anthraquinones occur in fungi and lichens, the other half being found in higher plants. A few anthraquinones have also been found to occur in bacteria and animals, e.g. insects. In most species, anthraquinones exist as complex mixtures of many different derivatives (Thomson, 1971). Since ancient times, natural anthraquinones extracted from plants and insects have been exploited for dyeing textiles, and the isolated pigments have been utilized in painter's colours as well (Schweppe, 1993). Anthraquinone pigments obtained from natural sources were widely used and highly esteemed, because of their intensive colours and excellent dye-

Abbreviations: $\mathrm{A}_{460}$, absorbance at wavelength $460 \mathrm{~nm}$; Ac, acetyl; Cl-Dr, 5-chlorodermorubin; D, dermocybin; D-Gluc $p$, dermocybin-1- $\beta$-D-glucopyranoside; Dr, dermorubin; E, emodin; Ec, endocrocin; E-Glucp, emodin1 - $\beta$-D-glucopyranoside; IMK, isopropylmethyl ketone; Rel. A, relative absorbance. ing and the light-fastness properties. Nowadays, less attention has been paid to the use of natural anthraquinones as textile and artist's colours, but instead there is growing interest in applying them as colouring agents for beverages, candies and other foods (Lancaster and Lawrence, 1996; Carvalho and Collins, 1997). Also the biochemical and pharmacological applications of anthraquinones are noteworthy, as some herbal anthraquinones are known to have important medicinal properties, e.g. antineoplastic activity and the activity of dissolving bladder and kidney stones (Cheng and Zee-Cheng, 1983; González et al., 1992; Tóth et al., 1993; Krizsán et al., 1996). Anthraquinones have also been used in analytical chemistry as chelating agents and, due to their optical properties, as chromophores in photometry, fluorimetry and in the study of photochemical reactions (Navas Diaz, 1991).

$\beta$-Glucosidases $[\beta$-D-glucoside glucohydrolase, EC 3.2.1.21] form a broad group of enzymes, common among plants, fungi, bacteria and animal tissues. $\beta$-Glucosidases display a diversity of substrate specificity, depending on the species of \section{.}


organism and their role in the producing cell. $\beta$-Glucosidases catalyze the hydrolysis of alkyl and aryl $\beta$-D-glucosides, as well as $\beta$-D-glucosides, containing only carbohydrate residues, e.g. cellobiose (Esen, 1993; Woodward and Wiseman, 1982). Nevertheless, also a $\beta$-glucosidase that exhibits the ability to hydrolyze both $\alpha$ - and $\beta$-glucosides has been found (Gueguen et al., 1995). In plants, $\beta$-glucosidases are involved in a variety of metabolic events and growth-related responses and they play an important regulatory role in biological processes (Esen, 1993; Duroux et al., 1998). Recently, research on $\beta$-glucosidases has resulted in significant scientific and economic applications. Intensive study has been performed to understand the process of enzyme-catalyzed hydrolysis of cellulose to glucose (Esen, 1993). Further, $\beta$-glucosidase-catalyzed hydrolysis has been applied to several interesting fields, such as protein engineering, composting, textile treatment and wine making (Garcia et al., 1995; Günata et al., 1996; Csiszár et al., 1998). $\beta$-Glucosidases also catalyze the reversal of the normal hydrolytic reaction and can hence be used in transglucosidations to synthesize di- and tri-saccharides (Furumoto et al., 1992; Bay et al., 1993; Christakopoulos et al., 1994a, 1994b) and even tetrasaccharides (Boon et al., 1998). There is growing interest in synthetic oligosaccharides owing to their inclusion in so-called functional foods, which are considered to be beneficial to human health (Boon et al., 1998). Pure $\beta$-glucosidase is found to have therapeutic use for treatment of some diseases (Woodward and Wiseman, 1982).

Though fungal $\beta$-glucosidases have been isolated from several species of fungi, reports on the activities of these enzymes in ectomycorrhizal fungi are rare; in this regard, we found only one report concerning Pisolithus tinctorius ( $\mathrm{CaO}$ and Crawford, 1993). The optimal $\mathrm{pH}$ for fungal $\beta$-glucosidases is in the range from $\mathrm{pH} 1.5$ to 7.0, being in most cases around $\mathrm{pH} 5.0$ (Woodward and Wiseman, 1982; Rumyantseva and Rodionova, 1982; Bedino et al., 1985; Li and Calza, 1991; Bhat et al., 1993; Cao and Crawford, 1993; Sasaki and Nagayama, 1994; Wei et al., 1996; Peralta et al., 1997; Pitson et al., 1997). The optimal temperature varies from 37 to $75^{\circ} \mathrm{C}$. Because we found no report on the $\mathrm{pH}$ optimum of the $\beta$-glucosidase in the fungus Dermocybe sanguinea, we adjusted the
$\mathrm{pH}$ for our experiments to the most frequently found optimal $\mathrm{pH}$-value of fungal $\beta$-glucosidases, i.e. $\mathrm{pH}$ 5.0.

In this study, our major objective was to develop a preparative method for the isolation of anthraquinone aglycones from the fungus $D$. sanguinea. We were interested in separating and characterizing the anthraquinone compounds occurring in the Scandinavian species and, further, in applying the pure compounds as dyes for textile materials in mechanical dyeing processes (Räisänen et al., in the press; Räisänen et al., in preparation). In this paper, we shall describe the isolation of the hydroxyanthraquinone aglycones using the endogenous $\beta$-glucosidase of the fungus for the enzymatic hydrolysis of the $O$-glycosyl linkage in emodin- and dermocybin-1- $\beta$-D-glucopyranosides. The developed enzymatic method will be shown to hydrolyze the $O$-glycosyl linkages virtually completely, affording two fractions of anthraquinones: Fraction 1 ( $94 \%$ of the total pigment amount), containing almost exclusively emodin and dermocybin, and Fraction $2(6 \%)$, containing mainly anthraquinone carboxylic acids. To estimate the effectiveness of the enzymatic hydrolysis, the anthraquinone glycosides were isolated from the fungus using extraction with water and acetone. TLC combined with densitometry-spectrophotometry was applied to the analysis of the components in the fractions. The composition of Fraction 1 was of main interest from the viewpoint of possible dyeing applications and was therefore more thoroughly analysed by combined GC-MS using derivatized samples.

\section{Experimental}

\section{Chemicals}

All chemicals, if not mentioned otherwise, were of analytical-reagent grade. Isopropylmethyl ketone was purchased from Fluka AG (Buchs, Switzerland), acetone and HPLC-grade ethyl acetate from Lab-Scan (Dublin, Ireland), pyridine and acetic anhydride from Riedel-de Haen AG (Seelze, Germany) and chloroform, toluene and formic acid $(100 \%)$ from E. Merck (Darmstadt, Germany). Ethanol was of Aa- or AaS-grade and purchased from Primalco (Rajamäki, Finland). Diazald (N-methyl-N-nitroso- $p$-toluenesulfonamide) was purchased from Aldrich-Chemical Co. 
(Steinheim, Germany), NaOH from Eka Nobel AB (Bohus, Sweden) and sodium acetate from E. Merck. TLC aluminium sheets precoated with silica gel 60 without fluorescent indicator were purchased from E. Merck.

\section{Instrumentation}

Densitometric measurements were carried out using a Shimadzu CS-930 densitometer-spectrophotometer equipped with an integrative printer DR-2 (Shimadzu, Kyoto, Japan). The instrument was operated in the reflection mode. The densitograms were recorded at wavelengths $460 \mathrm{~nm}$ (Fractions 1 and 2) or $480 \mathrm{~nm}$ (the water and acetone extracts). The electronic absorption spectra of the anthraquinone compounds in the region from 320 to $699 \mathrm{~nm}$ were measured directly from the spots on the TLC plates using the spectrophotometer of the Shimadzu CS-930 instrument. The blue fluorescing spots, caused by non-anthraquinone impurities, were observed to absorb in the UV-region. As these compounds were not completely separated from the anthraquinone derivatives, their UV-spectra overlapped those of the anthraquinones. Hence, the anthraquinone spectra were recorded only in the visible region.

For combined GC-MS, a Hewlett-Packard 5890 A gas-chromatograph (Hewlett-Packard Co., Waldbronn, Germany) was used. A capillary column HP-5 coated with 5\% phenyl methyl siloxane (column length $15 \mathrm{~m}$, diameter $0.32 \mathrm{~mm}$ and film thickness $0.25 \mu \mathrm{m}$ ) was used. The detector and injector port temperatures were 280 and $260{ }^{\circ} \mathrm{C}$, respectively. The temperature was programmed to hold $3 \mathrm{~min}$ at $200^{\circ} \mathrm{C}$ and was then allowed to rise to $260{ }^{\circ} \mathrm{C}$ at a rate of $5^{\circ} \mathrm{C} / \mathrm{min}$. Helium was used as a carrier gas at a flow rate of $45.0 \mathrm{ml} / \mathrm{min}$. The column effluent was introduced directly into the ion source of a JEOL JMS-SX 102 mass spectrometer (JEOL, Tokyo, Japan), which was operated in the electron impact mode (electron energy $70 \mathrm{eV}$, accelerating potential $10 \mathrm{kV}$ and ion source temperature $240^{\circ} \mathrm{C}$ ). Perfluorokerosene was used as an internal reference. The instrument resolution was 3000 .

\section{Isolation of anthraquinone aglycones by $\beta$-glucosidase hydrolysis}

Fig. 1 describes the protocol of the new enzymatic method, developed to isolate hydroxy- anthraquinone aglycones from the fungus $D$. sanguinea. A $10.5 \mathrm{~kg}$ amount of fresh fruit bodies of the fungus were collected from a spruce forest near Kuopio, Finland. A portion of $0.5-0.8 \mathrm{~kg}$ fungi was suspended into 1.0-1.5 l sodium acetate buffer $(0.075 \mathrm{M}, \mathrm{pH} 5.0)$ and the mixture was homogenized with an Ultra-Turrax homogenizer at full power for $4-5 \mathrm{~min}$ to bring the $\beta$-glucosidase enzyme and anthraquinone glucosides together. The procedure was repeated until all fruit bodies had been treated. Enzymatic hydrolysis by endogenous $\beta$-glucosidase was performed by allowing the mixture to react in a 251 plastic container for 2-3 days at room temperature. The clear, orange buffer extract (181) was then drained off through a tap and the fungal residue was filtered in a Büchner funnel with suction. The 71 amount of filtrate was combined with the main buffer extract to make a solution with a total volume of 251.

The fungal residue in the Büchner funnel was extracted with acetone until only pale colour was observed in the solution. Acetone was distilled off from the combined acetone extracts (total volume $40 \mathrm{l}$ ) and the residue was allowed to cool to room temperature. The formed precipitate was filtered in a Büchner funnel with suction and dried in an oven at $80^{\circ} \mathrm{C}$. The filtrate was discarded. The yield of Fraction 1, containing mainly emodin and dermocybin (structures in Fig. 2), was $56.0 \mathrm{~g}(0.54 \%$ of the fresh weight).

The pigments in the 251 volume of buffer extract were partitioned into suitable volumes of IMK and the organic phases were combined. The IMK solution was then concentrated to a small volume in a rotary evaporator. Thereafter, crystallization of anthraquinones occurred on cooling. The yield of Fraction 2, containing mainly hydroxyanthraquinone carboxylic acids, was $3.3 \mathrm{~g}$ ( $0.03 \%$ of the fresh weight).

\section{Isolation of anthraquinone glucosides}

The anthraquinone glucosides and anthraquinone carboxylic acids were isolated from $D$. sanguinea by the following procedure. A $c a .0 .5 \mathrm{~kg}$ portion of fresh fruit bodies of the fungi was suspended into 1.01 of boiling water. The suspension was boiled for $30 \mathrm{~min}$, allowed to cool to room temperature and then homogenized with an Ultra- 


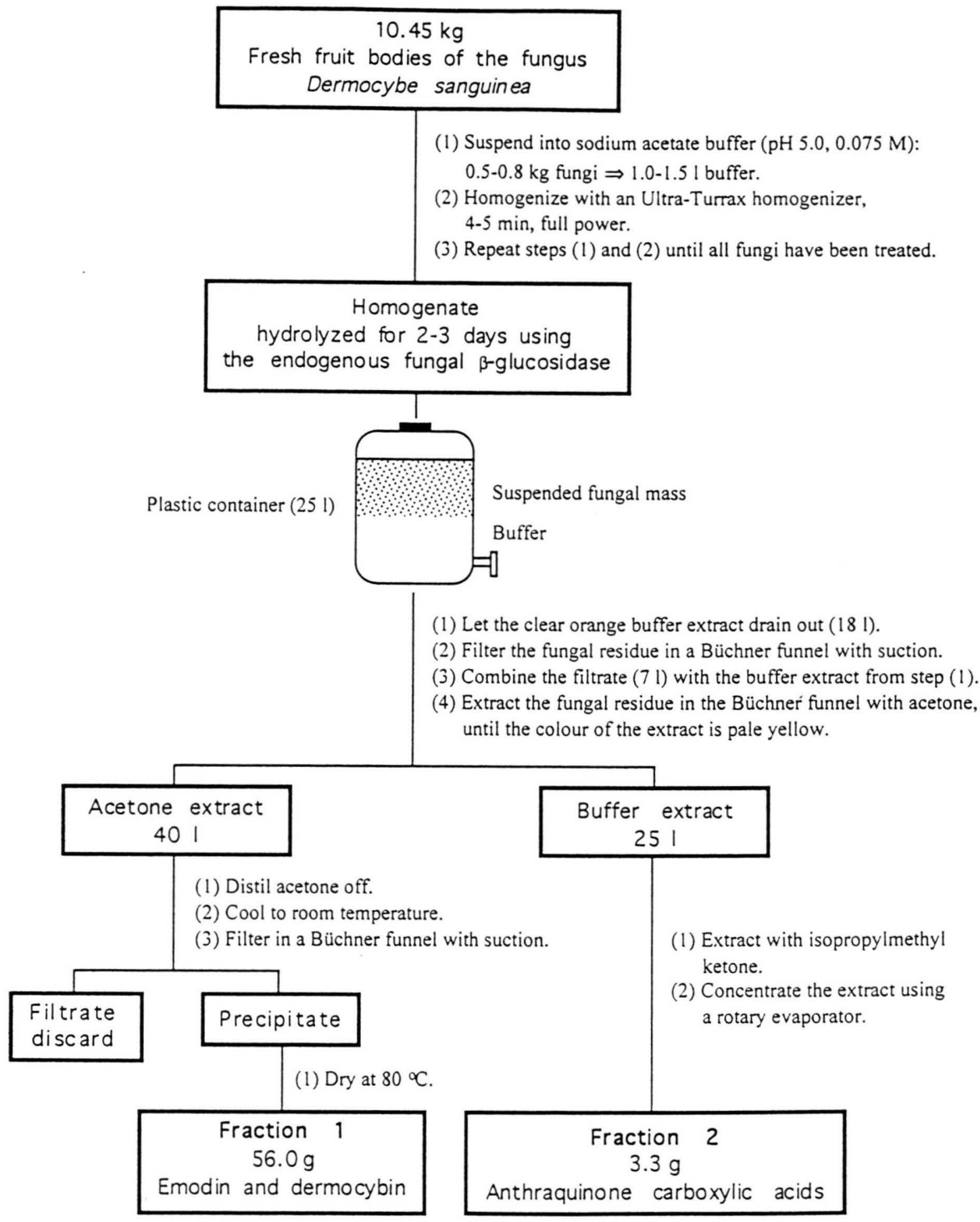

Fig. 1. Protocol for the isolation of the anthraquinone aglycones from the fungus $D$. sanguinea applying hydrolysis catalyzed by the endogenous $\beta$-glucosidase.

Turrax homogenizer for $4-5$ min using full power. The procedure was repeated until $1.35 \mathrm{~kg}$ of fungi had been treated. The combined homogenates were filtered in a Büchner funnel with suction. The fungal residue in the funnel was extracted with water, until the colour of the extract was pale. The water extracts were combined with the filtrate, resulting in a solution with a total volume of 5.51 . Thereafter, the fungal residue in the Büchner funnel was extracted with acetone, until the colour of the extract was pale. The pigment compositions of the final water extract and acetone extract were analyzed by TLC combined with densitometricspectrophotometric measurements (Figs. 4 and 5).

\section{TLC separations}

A glass chamber with internal dimensions of $21 \mathrm{~cm} \times 9 \mathrm{~cm} \times 24 \mathrm{~cm}$ was used for TLC developments. The inner walls of the chamber were lined 
with filter paper Whatman No. 1 (Whatman, Maidstone, England). A fixed volume $(200 \mathrm{ml})$ of the eluent, toluene-ethyl acetate-ethanolformic acid $(10: 8: 1: 2, \mathrm{v} / \mathrm{v} / \mathrm{v} / \mathrm{v})$, was poured into the chamber and the atmosphere was allowed to stabilize. The sample solution for TLC was prepared by dissolving a small amount of Fraction 1 or 2 in an appropriate volume of ethanol to give a transparent solution. A small volume of the water or acetone extract was diluted with ethanol to give a sample solution of an appropriate concentration. Suitable aliquots of the sample solutions were spotted onto a TLC plate $(4-10 \mathrm{~cm} \times 20 \mathrm{~cm}) 2 \mathrm{~cm}$ away from the lower edge of the plate, the borders and one another. The plate was placed into the TLC chamber and the solvent front was allowed to rise until it was about $2 \mathrm{~cm}$ from the upper edge. The line of the solvent front was marked and the plate was allowed to dry. The pigments on the TLC chromatograms were detected and characterized by densitometry-spectrophotometry.

\section{Derivatization of the Fraction 1 anthraquinones}

The anthraquinones of Fraction 1 were of main interest to us and, therefore, its composition was analyzed more thoroughly by GC-MS. To ensure sufficient volatility of the compounds, anthraquinones were methylated and acetylated. The methylations were performed with diazomethane in an apparatus described by Fales et al. (1973). For the reaction, $20 \mathrm{mg}$ of Fraction 1, dissolved in $2 \mathrm{ml}$ IMK, was placed into the outer tube of the apparatus and $107 \mathrm{mg}$ Diazald-reagent was placed into the inner tube. The system was closed with a clamp and attached to a stativ in a hood. A $0.3 \mathrm{ml}$ aliquot of $5 \mathrm{~N} \mathrm{NaOH}$ solution was injected through a sep- tum onto the Diazald-reagent and the liberated $\mathrm{CH}_{2} \mathrm{~N}_{2}$ was allowed to react with the compounds for $1 \mathrm{~h}$ at room temperature. After the reaction, the organic phase was washed with water and evaporated to dryness.

The acetylation of the HO-groups in the anthraquinones was performed with acetic anhydride in pyridine (Räisänen et al., in the press). For the GC-MS, $1 \mathrm{mg}$ of the derivatized sample was dissolved in $1 \mathrm{ml}$ of acetone.

\section{Results and Discussion}

\section{Enzymatic hydrolysis}

The enzymatic, preparative isolation procedure developed by us, was found to be very effective and simple to carry out. The endogenous $\beta$-glucosidase of the fungus possessed optimal substrate specificity and kinetic properties. The $O$-glycosyl linkages were hydrolyzed virtually completely, leaving only negligible amounts of emodin- and dermocybin-1- $\beta$-D-Glucp (structures in Fig. 2) into the water-soluble Fraction 2 (Räisänen et al., in the press).

Using the enzymatic isolation method, the yield of Fraction 1, i.e. emodin and dermocybin, was $0.54 \%$ of the fresh weight of the fungi. In comparison, the fresh-weight percentages reported by Steglich et al. (1969) for emodin and dermocybin were $0.15 \%$ and $0.06 \%$, respectively. Thus, the total amount of emodin and dermocybin obtained by us was over twice as high as the total amount of these pigments obtained by Steglich et al. (1969). Nevertheless, the total amount of anthraquinone carboxylic acids in Fraction 2 was similar to that obtained by Steglich et al. (1969), $0.03 \%$ of the<smiles>[R10]Oc1cc(C)cc2c1C(=O)c1c(O)c([R])c([R20])c([R])c1C2=O</smiles>

\begin{tabular}{|c|c|c|c|c|}
\hline $\mathrm{R} !$ & $\mathrm{R}^{5}$ & $\mathrm{R}^{6}$ & $\mathrm{R}^{7}$ & Glucosides and aglycones \\
\hline $\mathrm{H}$ & $\mathrm{H}$ & $\mathrm{H}$ & $\mathrm{H}$ & Emodin \\
\hline Glucp & $\mathrm{H}$ & $\mathrm{H}$ & $\mathrm{H}$ & Emodin-1- $\beta$-D-Glucp $p$ \\
\hline $\mathrm{H}$ & $\mathrm{OH}$ & $\mathrm{CH}_{3}$ & $\mathrm{OH}$ & Dermocybin \\
\hline Glucp & $\mathrm{OH}$ & $\mathrm{CH}_{3}$ & $\mathrm{OH}$ & Dermocybin-1- $\beta$-D-Glucp \\
\hline $\mathrm{H}$ & $\mathrm{H}$ & $\mathrm{CH}_{3}$ & $\mathrm{H}$ & Physcion \\
\hline
\end{tabular}<smiles>[R20]c1cc(O)c([R2])c2c1C(=O)c1c([R])c(C)c(C(=O)O)c(O)c1C2=O</smiles>

\begin{tabular}{llll}
\hline $\mathrm{R}^{4}$ & $\mathrm{R}^{5}$ & $\mathrm{R}^{8}$ & Carboxylic acids \\
\hline $\mathrm{H}$ & $\mathrm{H}$ & $\mathrm{H}$ & Endocrocin \\
$\mathrm{OH}$ & $\mathrm{H}$ & $\mathrm{CH}_{3}$ & Dermorubin \\
$\mathrm{OH}$ & $\mathrm{Cl}$ & $\mathrm{CH}_{3}$ & 5-Chlorodermorubin \\
\hline
\end{tabular}

Fig. 2. Structures of the anthraquinones. 
fresh weight. Apparently, the use of the endogenous $\beta$-glucosidase in the isolation enabled a virtually complete hydrolysis of the $O$-glycosyl linkages, thus leading to a high yield of the emodin and dermocybin aglycones.

\section{TLC densitometry-spectrophotometry}

Fig. 3 shows the TLC chromatograms and their densitograms produced by the anthraquinone aglycones in Fractions 1 and 2. The densitograms in Fig. 3 demonstrate that there are no anthraquinone glucosides present in the fractions, isolated after the enzymatic hydrolysis. Fig. 3A illustrates that the main component, emodin $\left(R_{\mathrm{f}}=0.63\right)$, has moved on the TLC plate as a narrow, very intensive spot, whereas dermocybin $\left(R_{\mathrm{f}}=0.53\right)$ has experienced excessive broadening (tailing). Visually, only the spots of emodin and dermocybin were observed, but under UV-light, the differently fluo-

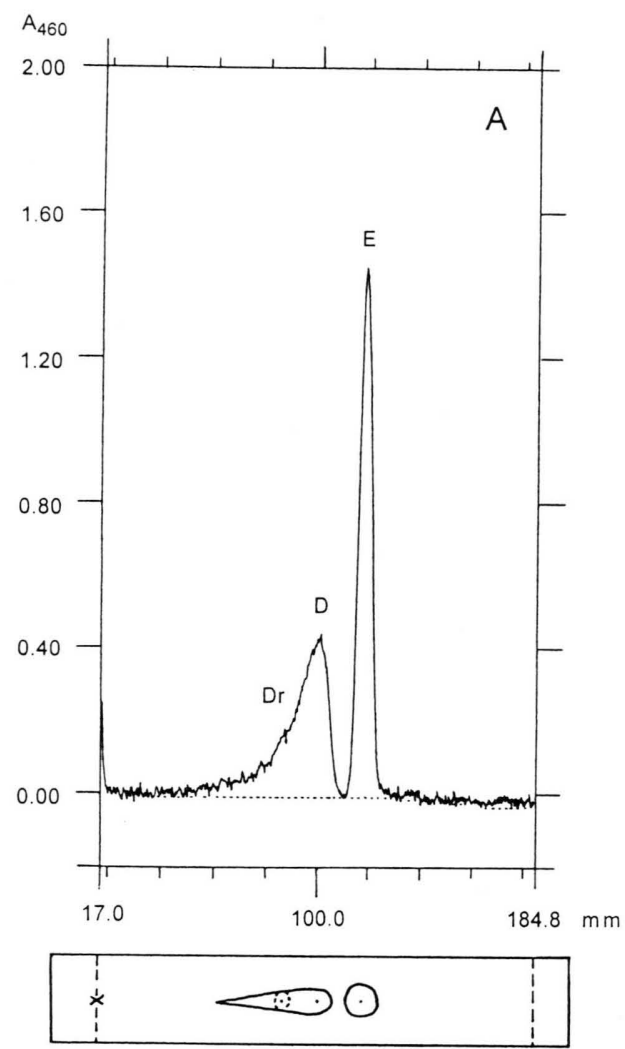

rescing spot of dermorubin $\left(R_{\mathrm{f}}=0.44\right.$, structure in Fig. 2) could be distinguished, in spite of the overlapping long tail of dermocybin. In the densitogram of Fig. 3A, the shoulder on the left wing of the dermocybin peak also indicates the presence of dermorubin. The GC-MS analysis revealed that Fraction 1 contained very small amounts of dermorubin, endocrocin and physcion (Fig. 2), which were not observed on the TLC plate, due to their low concentration. The results of the GC-MS analysis are explained in further details in a separate chapter (vide infra).

Fig. 3B shows the TLC chromatogram and densitogram produced by Fraction 2, containing mainly anthraquinone carboxylic acids. Three spots were observed on the TLC plate: emodin $\left(R_{\mathrm{f}}=0.63\right)$, endocrocin $\left(R_{\mathrm{f}}=0.54\right)$ and a third spot, containing dermorubin $\left(R_{\mathrm{f}}=0.44\right)$ and possibly also 5-chlorodermorubin $\left(R_{\mathrm{f}}=0.44\right)$ (structures in Fig. 2). In the densitogram B, the concen-

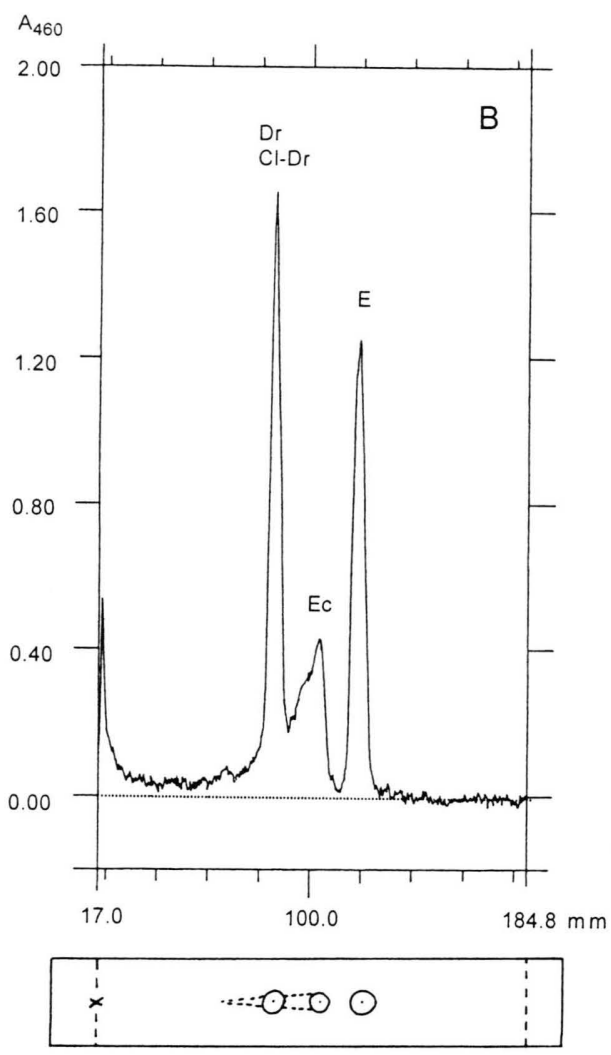

Fig. 3. TLC chromatograms and densitograms produced by the anthraquinone aglycones in Fraction 1 (A) and Fraction 2 (B). Conditions as in the experimental section. For the $R_{\mathrm{f}}$-values see the text. Structures of the compounds are shown in Fig. 2. 
tration profile of endocrocin shows excessive broadening. Small amounts of some additional anthraquinones can be hidden under the Ec profile or the noise of the baseline.

The TLC chromatograms and densitograms produced by the anthraquinone derivatives in the water and acetone extracts (see the paragraph for the non-enzymatic isolation) are presented in Fig. 4. The TLC chromatogram and densitogram afforded by the pigments of the water extract (Fig. 4A) indicate clearly emodin-1- $\beta$-D-glucopyranoside $\left(R_{\mathrm{f}}=0.10\right)$ and dermocybin-1- $\beta$-D-glucopyranoside $\left(R_{\mathrm{f}}=0.07\right)$ to be the main components in the water-soluble fraction. The densitogram A displays a relatively intense peak for dermorubin and the possible 5-chlorodermorubin $\left(R_{\mathrm{f}}=0.33\right)$, whereas only very low peaks can be observed for emodin $\left(R_{\mathrm{f}}=0.61\right)$ and dermocybin $\left(R_{\mathrm{f}}=0.51\right)$. The densitogram in Fig. 4B, produced by the pigments of the acetone extract exhibits clearly higher peaks for emodin and dermocybin as com-

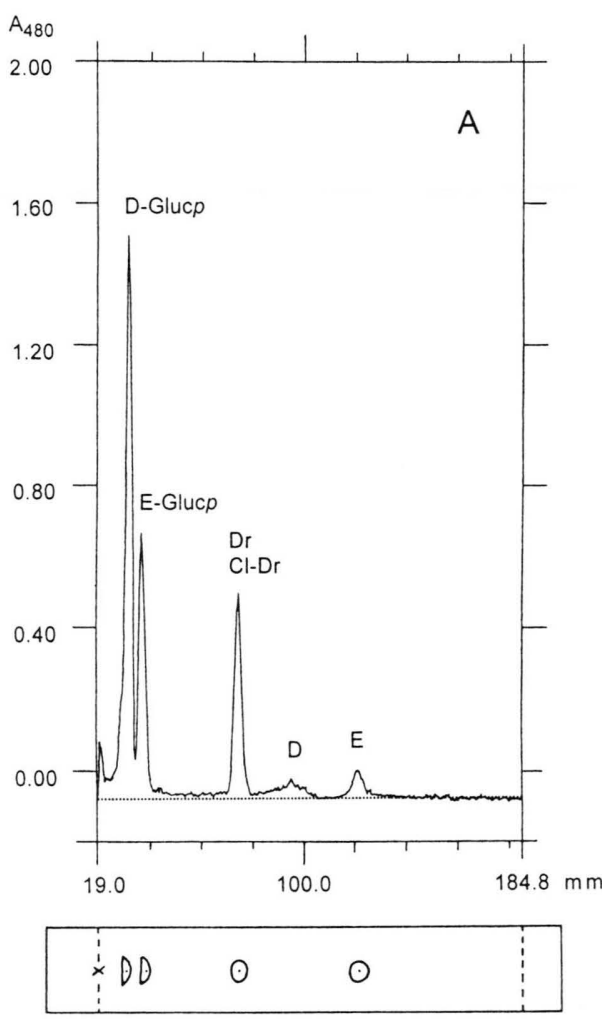

pared with the corresponding peaks in Fig. 4A. This indicates that the emodin and dermocybin are both much more soluble in acetone than in water. Figs. 4A and $\mathrm{B}$ also verify that emodin and dermocybin exist in the fungus predominantly as glucosides. According to Steglich and Lösel (1972), over $90 \%$ of emodin and dermocybin occur in the form of glucosides in the fungus $D$. sanguinea.

Two sets of electronic absorption spectra are compared in Fig. 5 for each of the main compounds, emodin and dermocybin as well as emodin- and dermocybin-1- $\beta$-D-Glucps. The solid-line spectra were measured after separation directly from the spots of the pure compounds on the TLC plate. The broken line shows the spectra measured in ethanol (emodin) or methanol (dermocybin, emodin- and dermocybin-1- $\beta$-D-Gluc $p$ s). As can be seen, the spectra measured from the spot and from the solution are quite consistent for emodin (A), emodin-1- $\beta$-D-Glucp (B) and dermocybin-1$\beta$-D-Glucp (D) regarding both the position $\left(\lambda_{\max }\right)$

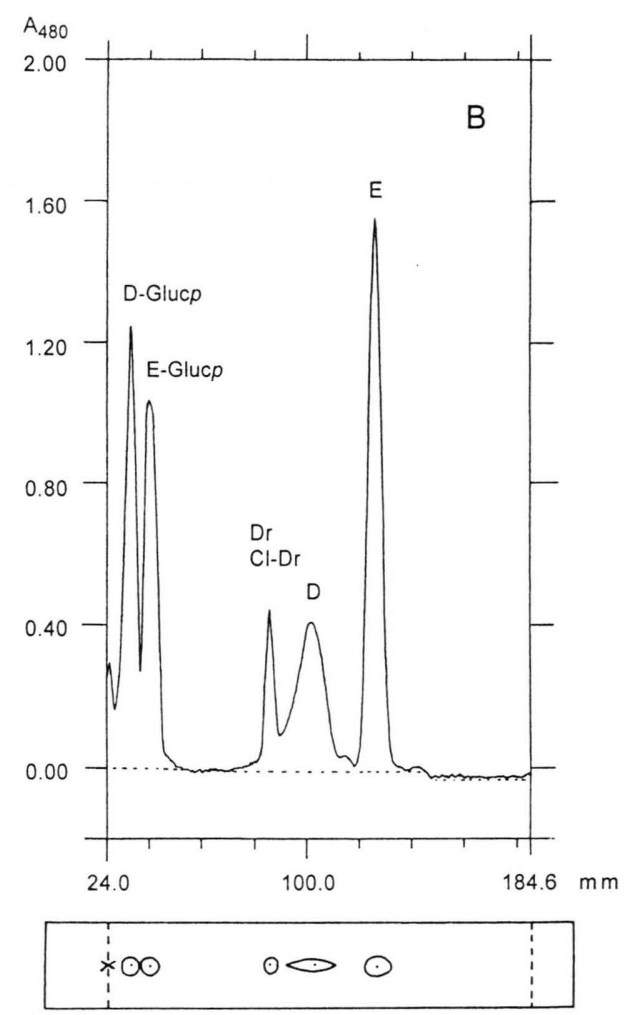

Fig. 4. TLC chromatograms and densitograms produced by the anthraquinone derivatives in the water extract (A) and the acetone extract (B) from the non-enzymatic isolation. Conditions as in the experimental section. For the $R_{\mathrm{f}}$-values see the text. Structures of the compounds are shown in Fig. 2. 


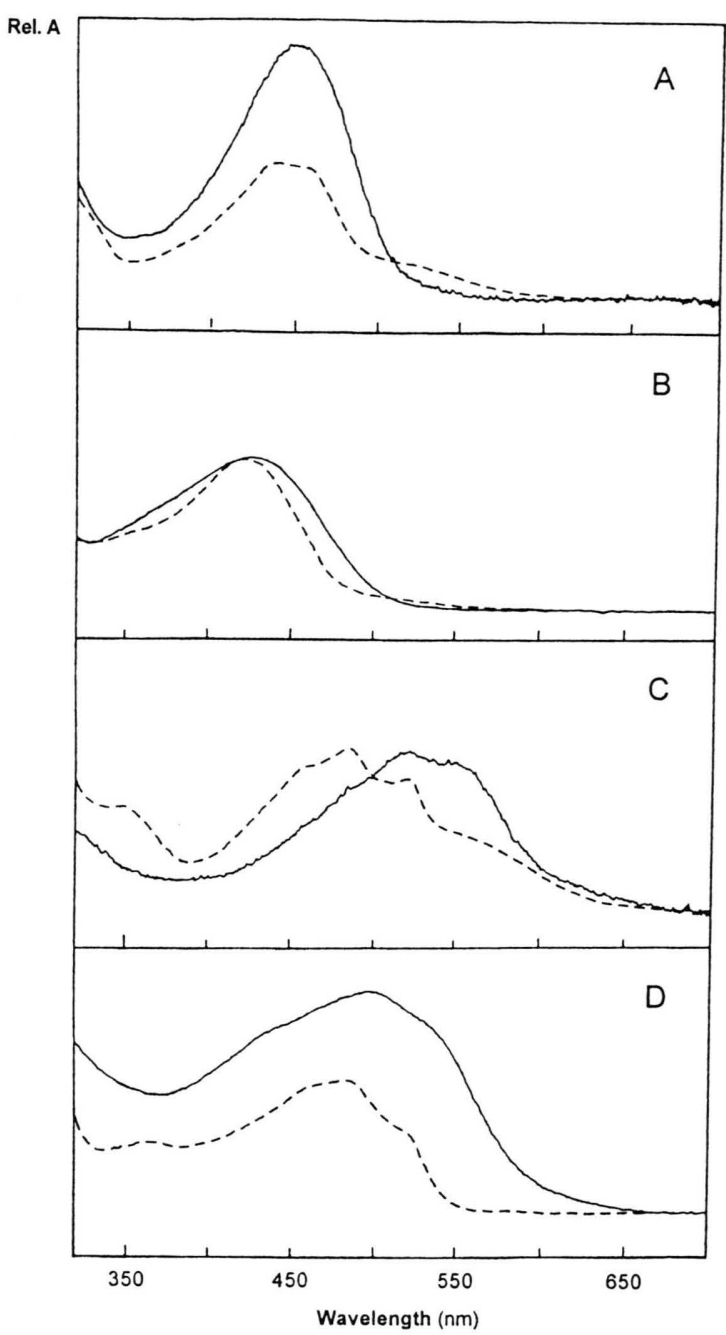

Fig. 5. Electronic absorption spectra of emodin (A), emodin-1- $\beta$-D-Glucp (B), dermocybin (C) and dermocybin$1-\beta-D-G l u c p$ (D) measured directly from the spot on the TLC plate (- $)$ and from the solution $(----)$. Conditions for the spot spectra as in the experimental section and for the solution spectra as previously described (Räisänen et al., in the press).

and the fine structure of the main absorption band. The spectra of dermocybin (C) show the greatest difference for the $\lambda_{\text {max }}$-values of the bands. A likely reason for this difference can be the aggregation of the dermocybin molecules in the spot on evaporation of the solvent molecules.

The densitometric-spectrophotometric measurements directly from the chromatograms were found to be an easy and rapid method to obtain more detailed information from the separated components. Especially, the possibility to measure the electronic absorption spectra directly from the spots facilitated appreciably the identification of the compounds. The densitometric measurement combined with the integration option also enabled the rough quantitative estimation of the percentages of different components, as the integrated area under each peak in the densitogram was related to the amount of material in the spot. The molar absorptivities $(\varepsilon)$ of the anthraquinone compounds in the silica medium differ, however, from one another and from the $\varepsilon$-values measured in ethanol. Hence, the peak areas are not directly comparable. For example, the $\varepsilon$-values of emodin$1-\beta-\mathrm{D}-$ Gluc $p$ are noticeably lower for all the absorption bands than the $\varepsilon$-values of dermocybin-1$\beta$-D-Glucp (Steglich and Lösel, 1972). These differences in the $\varepsilon$-values may explain why the intensities of the D-Glucp absorption peaks are clearly higher than those of E-Glucp in the densitograms of Fig. 4A and B, even though E-Glucp should be the more abundant compound in D. sanguinea according to previous studies (Steglich et al., 1969; Steglich and Lösel, 1972).

\section{GC-MS analysis of derivatized anthraquinones of Fraction 1}

Table I describes the GC-MS data of the methylated and acetylated anthraquinone derivatives of Fraction 1. The gas chromatogram showed sharp peak shapes and good resolution. On the basis of the MS data, peaks 1-5 were identified to represent derivatives of physcion, emodin, dermorubin, endocrocin and dermocybin, respectively (Table I).

The structures of the derivatives shown in Table I are consistent with the MS data of peaks $1-5$. These structures indicate that the methylations and acetylations of the Fraction 1 anthraquinones occurred with interesting regioselectivity. In the gas chromatogram, the intensity of peak 1 , representing physcion diacetate, was much higher than that of peak 2, assigned to emodin triacetate, although emodin was identified as the most abundant anthraquinone in Fraction 1 (Fig. 3A). This discrepancy in the results can be explained in terms of the hydrogen-bonding possibilities in emodin during the diazomethane methylation, which was performed in the IMK solvent. In this 
Table I. Retention and mass spectral data of the derivatized anthraquinones of Fraction 1.

\begin{tabular}{|c|c|c|c|c|c|}
\hline $\begin{array}{l}\text { Peak } \\
\text { no. }\end{array}$ & Compound & $\begin{array}{l}\text { Molecular } \\
\text { formula }\end{array}$ & Chemical structure & $\begin{array}{l}\text { Retention } \\
\text { time/min }\end{array}$ & $\begin{array}{l}\text { MS data } \\
\mathrm{m} / \mathrm{z}\end{array}$ \\
\hline 1 & $\begin{array}{l}\text { Physcion } \\
\text { diacetate }\end{array}$ & $\begin{array}{l}\mathrm{C}_{20} \mathrm{O}_{7} \mathrm{H}_{16} \\
(368.0896)\end{array}$ & $\mathrm{H}_{3} \mathrm{CO}$ & 10.47 & $\begin{array}{l}368(2 \%)[\mathrm{M}]^{+}, 326(23)[\mathrm{M}-\mathrm{Ac}+ \\
\mathrm{H}]^{+}, 284(100)[\mathrm{M}-2 \mathrm{Ac}+2 \mathrm{H}]^{+}, 255 \\
(7)[\mathrm{M}-2 \mathrm{Ac}+2 \mathrm{H}-\mathrm{CHO}]^{+}, 241(2) \\
{\left[\mathrm{M}-2 \mathrm{Ac}+2 \mathrm{H}-\mathrm{CHO}-\mathrm{CH}_{3}+\mathrm{H}\right]^{+}} \\
227(6)[\mathrm{M}-2 \mathrm{Ac}+2 \mathrm{H}-\mathrm{CHO}- \\
\left.2 \mathrm{CH}_{3}+2 \mathrm{H}\right]^{+} .\end{array}$ \\
\hline 2 & $\begin{array}{l}\text { Emodin } \\
\text { triacetate }\end{array}$ & $\begin{array}{l}\mathrm{C}_{21} \mathrm{O}_{8} \mathrm{H}_{16} \\
(396.0845)\end{array}$ & $\mathrm{AcO}$ & 11.63 & $\begin{array}{l}396(1 \%)[\mathrm{M}]^{+}, 354(27)[\mathrm{M}-\mathrm{Ac}+ \\
\mathrm{H}]^{+}, 312(17)[\mathrm{M}-2 \mathrm{Ac}+2 \mathrm{H}]^{+}, 284 \\
(6)[\mathrm{M}-2 \mathrm{Ac}+2 \mathrm{H}-\mathrm{CO}]^{+}, 270(100) \\
{[\mathrm{M}-3 \mathrm{Ac}+3 \mathrm{H}]^{+}, 241(8)[\mathrm{M}-3 \mathrm{Ac}} \\
+3 \mathrm{H}-\mathrm{CHO}]^{+}, 213(5)[\mathrm{M}-3 \mathrm{Ac}+ \\
3 \mathrm{H}-\mathrm{CHO}-\mathrm{CO}]^{+} .\end{array}$ \\
\hline 3 & $\begin{array}{l}\text { Dermorubin } \\
\text { diacetate }\end{array}$ & $\begin{array}{l}\mathrm{C}_{21} \mathrm{O}_{10} \mathrm{H}_{16} \\
(428.0743)\end{array}$ & $\mathrm{AcO}$ & 12.04 & $\begin{array}{l}428(10 \%)[\mathrm{M}]^{+}, 386(100)[\mathrm{M}-\mathrm{Ac}+ \\
\mathrm{H}]^{+}, 344(94)[\mathrm{M}-2 \mathrm{Ac}+2 \mathrm{H}]^{+}, 329 \\
(33)\left[\mathrm{M}-2 \mathrm{Ac}+2 \mathrm{H}-\mathrm{CH}_{3}\right]^{+}, 315 \\
(29)\left[\mathrm{M}-2 \mathrm{Ac}+2 \mathrm{H}-\mathrm{CHO}^{+}, 301\right. \\
(16)\left[\mathrm{M}-2 \mathrm{Ac}+2 \mathrm{H}-\mathrm{CH}_{3}-\mathrm{CO}^{+},\right. \\
284(16)\left[\mathrm{M}-2 \mathrm{Ac}+2 \mathrm{H}-\mathrm{CH}_{3}-\right. \\
\left.\mathrm{CO}_{2}-\mathrm{H}\right]^{+}, 272(5), 255(4), 235(11)\end{array}$ \\
\hline 4 & $\begin{array}{l}\text { Endocrocin } \\
\text { diacetate }\end{array}$ & $\begin{array}{l}\mathrm{C}_{20} \mathrm{O}_{9} \mathrm{H}_{14} \\
(398.0638)\end{array}$ & $\mathrm{AcO}^{-}$ & 12.24 & $\begin{array}{l}398(6 \%)[\mathrm{M}]^{+}, 356(100)[\mathrm{M}-\mathrm{Ac}+ \\
\mathrm{H}]^{+}, 314(97)[\mathrm{M}-2 \mathrm{Ac}+2 \cdot \mathrm{H}]^{+}, 298 \\
(36)[\mathrm{M}-2 \mathrm{Ac}+2 \mathrm{H}-\mathrm{O}]^{+}, 296(46) \\
{\left[\mathrm{M}-2 \mathrm{Ac}+2 \mathrm{H}-\mathrm{H}_{2} \mathrm{O}\right]^{+}, 285(37)} \\
{\left[\mathrm{M}-2 \mathrm{Ac}+2 \mathrm{H}-\mathrm{CHO}^{+}, 271(18)\right.} \\
{\left[\mathrm{M}-2 \mathrm{Ac}+2 \mathrm{H}-\mathrm{CO}_{2}+\mathrm{H}\right]^{+}, 271} \\
(18)\left[\mathrm{M}-2 \mathrm{Ac}+2 \mathrm{H}-\mathrm{CHO}-\mathrm{CH}_{3}\right. \\
+\mathrm{H}]^{+}, 255(8), 227(6), 200(14) .\end{array}$ \\
\hline 5 & $\begin{array}{l}\text { Dermocybin } \\
\text { triacetate with a } \\
\text { methylated } \mathrm{OH} \\
\text { at C-7 }\end{array}$ & $\begin{array}{l}\mathrm{C}_{23} \mathrm{O}_{10} \mathrm{H}_{20} \\
(456.1056)\end{array}$ & $\begin{array}{l}\mathrm{H}_{3} \mathrm{CO} \\
\mathrm{H}_{3} \mathrm{CO}\end{array}$ & 13.59 & $\begin{array}{l}456(2 \%)[\mathrm{M}]^{+}, 414(16)[\mathrm{M}-\mathrm{Ac}+ \\
\mathrm{H}]^{+}, 372(56)[\mathrm{M}-2 \mathrm{Ac}+2 \mathrm{H}]^{+}, 330 \\
(100)[\mathrm{M}-3 \mathrm{Ac}+3 \mathrm{H}]^{+}, 315(6)[\mathrm{M}- \\
\left.3 \mathrm{Ac}+3 \mathrm{H}-\mathrm{CH}_{3}\right]^{+}, 312(5)[\mathrm{M}-3 \mathrm{Ac} \\
\left.+3 \mathrm{H}-\mathrm{H}_{2} \mathrm{O}\right]^{+}, 297(3)[\mathrm{M}-3 \mathrm{Ac}+ \\
\left.3 \mathrm{H}-\mathrm{H}_{2} \mathrm{O}-\mathrm{CH}_{3}\right]^{+}, 284(3)[\mathrm{M}- \\
\left.3 \mathrm{Ac}+3 \mathrm{H}-\mathrm{H}_{2} \mathrm{O}-\mathrm{CO}\right]^{+} .\end{array}$ \\
\hline
\end{tabular}

solvent, the $\mathrm{C}-1$ and $\mathrm{C}-8 \mathrm{HO}$-groups formed relatively strong six-membered hydrogen chelate rings with the nearest $\mathrm{C}=\mathrm{O}$ oxygen in emodin. The intramolecular hydrogen bonds were strong enough to make the two hydroxyls unreactive towards diazomethane. Hence, a major part of the isolated C-6 HO-goups became regioselectively methylated by diazomethane, a minor part of the groups remaining free. Under the acetylation conditions with acetic anhydride in pyridine, all the nonmethylated HO-groups were esterified, as the intramolecular hydrogen bonds were not strong enough under those conditions.

The formation of the monomethylated dermocybin triacetate (the second highest peak 5 in the chromatogram), can be interpreted by comparable 
regioselectivities for the methylation and the acetylation reactions. Now the C-1, C-5 and C-8 HOgroups formed strong hydrogen bonds with the nearby carbonyl oxygens and were not methylated with diazomethane. Consequently, only the isolated $\mathrm{C}-7 \mathrm{HO}$-group was methylated. In the acetylation step, all the non-methylated HO-groups were esterified.

The regioselectivities of the methylation and acetylation reactions yielding the dermorubin and endocrocin diacetates (peaks 3 and 4) are more difficult to explain, but can be understood in the terms of the following interpretations. The nonreactivity of the C-1, C-4 (in dermorubin) and C-6 HO-groups with diazomethane in IMK can be explained by the formation of sandwich dimers, in which the two molecules are held together by $\pi-\pi$ interactions between the two $\pi$-systems and by two pairs of intermolecular hydrogen bonds formed between the 2-COOH group of one molecule and the 6-OH group of the counterpart mole- cule, as shown in Fig. 6 for dermorubin. Inspection of the molecular model constructed for dermorubin by means of HSG Molecular Structure Models, B Set for Organic Chemistry (Maruzen, Japan), indicated that the formation of such dimers is sterically very likely. The non-reactivity of the $1-\mathrm{OH}$ group of dermorubin in the acetylation step following the methylation, can be explained by the formation of an exceptionally strong intramolecular hydrogen bond between the 2-COOH and the 1-OH. This hydrogen bond was strong enough to remain intact even under the acetylation conditions, whereas the other non-methylated HOgroups became acetylated.

\section{Acknowledgements}

The authors thank the City of Kuopio, the Foundation for Research of Natural Resources in Finland and the Foundation for Commercial and Technical Sciences for financial support to this study.

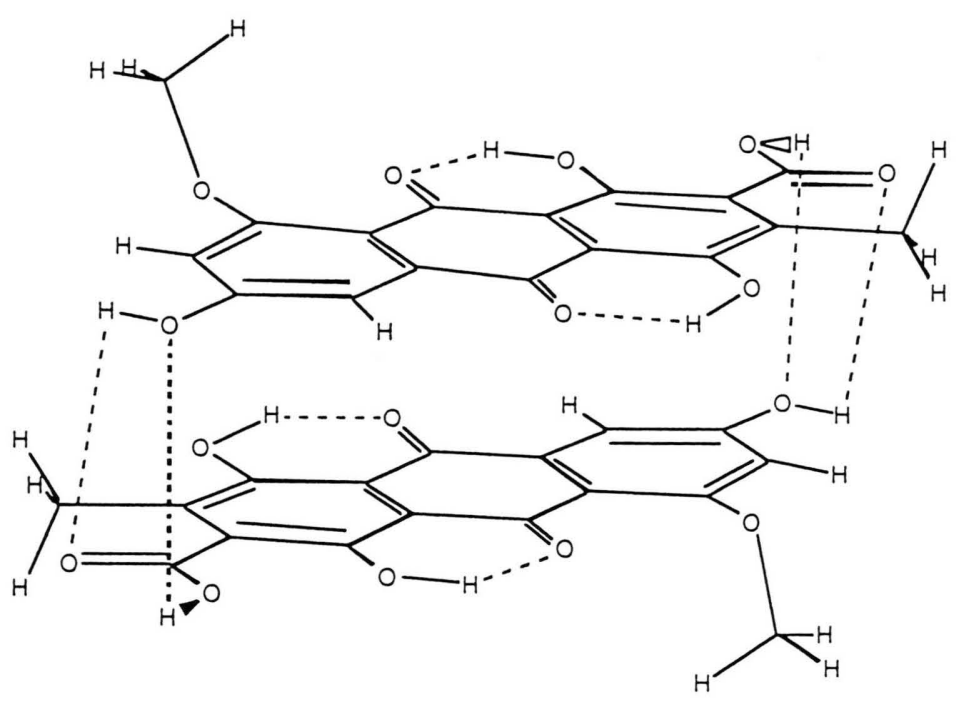

Fig. 6. Structure of the dermorubin sandwich dimer.
Bay S., Namane A. and Cantacuzene D. (1993), Enzymatic synthesis of disaccharide-serine and peptide conjugates. BioMed. Chem. Lett. 3, 2515-2520.

Bedino S., Testore G. and Obert F. (1985), Comparative study of glucosidases from the thermophilic fungus Thermoascus aurantiacus: purification and characterization of intracellular $\beta$-glucosidase. Italian J. Biochem. (English ed.) 34, 341-355.

Bhat K. M., Gaikwad J. S. and Maheshwari R. (1993), Purification and characterization of an extracellular $\beta$-glucosidase from the thermophilic fungus Sporotri- chum thermophile and its influence on cellulase activity. J. Gen. Microbiol. 139, 2825-2832.

Boon M. A., van der Oost J., de Vos W. M., Janssen A. E. M. and van't Riet K. (1998), Synthesis of oligosaccharides catalyzed by thermostable $\beta$-glucosidase from Pyrococcus furiosus. Appl. Biochem. Biotech. 75, 269-278.

Cao W. and Crawford D. L. (1993), Purification and some properties of $\beta$-glucosidase from the ectomycorrhizal fungus Pisolithus tinctorius strain SMF. Can. J. Microbiol. 39, 125-129. 
Carvalho P. R. N. and Collins C. H. (1997), HPLC determination of carminic acid in foodstuffs and beverages using diode array and fluorescence detection. Chromatogr. 45, 63-66.

Cheng C. C. and Zee-Cheng R. K. Y. (1983), The design, synthesis and development of a new class of potent antineoplastic anthraquinones, in: Progr. Med. Chem., Vol. 20 (Ellis G. P. and West G. B., ed.). Elsevier Science Publishers B. V., Amsterdam.

Christakopoulos P., Bhat M. K., Kekos D. and Macris B. J. (1994a), Enzymatic synthesis of trisaccharides and alkyl $\beta$-D-glucosides by the transglycosylation reaction of $\beta$-glucosidase from Fusarium oxysporum. Int. J. Biol. Macromol. 16, 331-334.

Christakopoulos P., Kekos D., Macris B. J., Goodenough P. W. and Bhat M. K. (1994b), Optimization of $\beta$-glucosidase catalysed synthesis of trisaccharides from cellobiose and gentiobiose. Biotechol. Lett. 16, $587-592$.

Csiszár E., Szakács G. and Rusznák I. (1998), Combining traditional cotton scouring with cellulase enzymatic treatment. Text. Res. J. 68, 163-167.

Duroux L., Delmotte F. M., Lancelin J.-M., Kéravis G. and Jay-Allemand C. (1998), Insight into naphthoquinone metabolism: $\beta$-glucosidase-catalysed hydrolysis of hydrojuglone $\beta$-D-glucopyranoside. Biochem. J. 333, 275-283.

Esen A. (1993), $\beta$-Glucosidases: overview. In: $\beta$-Glucosidases: Biochemistry and Molecular Biology (Esen A., ed.). American Chemical Society, Washington, D. C., pp. $1-14$

Fales H. M., Jaouni T. M. and Babashak J. F. (1973), Simple device for preparing ethereal diazomethane without resorting to codistillation. Anal. Chem. 45, $2302-2303$.

Furumoto T., Kameda Y. and Matsui K. (1992), Enzymatic synthesis of glucoside derivatives of validamine and valienamine. Chem. Pharm. Bull. 40, $1871-1875$.

Garcia C., Moreno J. L., Hernandez T., Costa F. and Polo A. (1995), Effect of composting on sewage sludges contaminated with heavy metals. Bioresource Technology 53, 13-19.

González A. G., Bermejo Barrera J., Barba Davila B., Valencia E. and Dominguez X. A. (1992), Anthraquinones from Cassia greggii. Phytochemistry 31, 255258.

Gueguen Y., Chemardin P., Arnaud A. and Galzy P. (1995), Purification and characterization of an intracellular $\beta$-glucosidase from Botrytis cinerea. Enzyme Microb. Technol. 17, 900-906.

Günata Z., Vallier M. J., Sapis J. C., Bayonove C., Arnaudon V., Madarro A. and Polaina J. (1996), Hydrolysis of monoterpenyl- $\beta$-D-glucosides by cloned $\beta$-glucosidases from Bacillus polymyxa. Enzyme Microb. Technol. 18, 286-290.
Krizsán K., Szókán G., Tóth Z. A., Hollósy F., László M. and Khlafulla A. (1996), HPLC analysis of anthraquinone derivatives in madder root (Rubia tinctorum) and its cell cultures. J. Liq. Chromatogr. 19, 2295-2314.

Lancaster F. E. and Lawrence J. F. (1996), High-performance liquid chromatographic separation of carminic acid, $\alpha$ - and $\beta$-bixin, and $\alpha$ - and $\beta$-norbixin, and the determination of carminic acid in foods. J. Chromatogr. A 732, 394-398.

Li X. and Calza R. E. (1991), Purification and characterization of an extracellular $\beta$-glucosidase from the rumen fungus Neocallimastix frontalis EB 188. Enzyme Microb. Technol. 13, 622-628.

Navas Diaz A. (1991), Analytical applications of 1,10-anthraquinones: a review. Talanta 38, 571-588.

Peralta R. M., Kadowaki M. K., Terenzi H. F. and Jorge J. A. (1997), A highly thermostable $\beta$-glucosidase from the thermophilic fungus Humicola grisea var. thermoidea: purification and biochemical characterization. FEMS Microbiol. Lett. 146, 291-295.

Pitson S. M., Seviour R. J. and McDougall B. M. (1997), Purification and characterization of an extracellular $\beta$-glucosidase from the filamentous fungus Acremonium persicum and its probable role in $\beta$-glucan degradation. Enzyme Microb. Technol. 21, 182-190.

Rumyantseva G. N. and Rodionova N. A. (1982), Properties of $\beta$-glucosidase (EC 3.2.1.21) from the cellulolytic fungus Geotrichum candidum 3c. Biokhimiya 47, $108-114$.

Sasaki I. and Nagayama H. (1994), $\beta$-Glucosidase from Botrytis cinerea: its relation to the pathogenicity of this fungus. Biosci. Biotech. Biochem. 58, 616-620.

Schweppe H. (1993), Handbuch der Naturfarbstoffe, ecomed, Landsberg/Lech.

Steglich W. and Lösel W. (1972), Anthrachinon-glucoside aus Dermocybe sanguinea (Wulf. ex Fr.) Wünsche. Chem. Ber. 105, 2928-2932.

Steglich W., Lösel W. and Austel V. (1969), Anthrachinon-Pigmente aus Dermocybe sanguinea (Wulf. ex Fr.) Wünsche and D. semisanguinea (Fr.). Chem. Ber. 102, 4104-4118.

Thomson R. H. (1971), Naturally occurring quinones, 2nd Ed., Academic Press, London.

Tóth Z. A., Raatikainen O., Naaranlahti T. and Auriola S. (1993), Isolation and determination of alizarin in cell cultures of Rubia tinctorum and emodin in Dermocybe sanguinea using solid-phase extraction and high-performance liquid chromatography. J. Chromatogr. 630, 423-428.

Wei D. L., Kirimura K., Usami S. and Lin T. H. (1996), Purification and characterization of an extracellular $\beta$-glucosidase from the wood-grown fungus Xylaria regalis. Curr. Microbiol. 33, 297-301.

Woodward J. and Wiseman A. (1982), Fungal and other $\beta$-D-glucosidases - their properties and applications. Enzyme Microb. Technol. 4, 73-79. 